\title{
Minimum dietary standardized ileal digestible isoleucine to leucine ratio for laying hens
}

\author{
J.W. Spek \\ Wageningen Livestock Research
}

CVB Documentation report nr. 75

June 2018

https://doi.org/10.18174/455525

Wageningen Livestock Research

P.O. Box 338

$6700 \mathrm{AH}$ Wageningen

The Netherlands 


\section{(c) Federatie Nederlandse Diervoederketen 2017}

No part of this edition may be copied, photocopied, reproduced, translated or reduced to any electronic medium or machine-readable form, in whole or in part, without specific written permission of the Federatie Nederlandse Diervoederketen (info@diervoederketen.nl).

All copyrights and database rights with respect to this publication are expressly reserved. Nothing in this publication may be reproduced, copied, retrieved, made public or re-used or made available in any way whatsoever to third parties by way of printing, photocopying, microfilm or in any other way unless the Federatie Nederlandse Diervoederketen has given express written permission to do so. This publication has been compiled with great care; however, the Federatie Nederlandse Diervoederketen and Wageningen Livestock Research cannot be held liable in any way for the consequences of using the information in this publication. 


\section{Preface}

In 2017 a new Table has been introduced called; Table 'Standardized ileal digestibility of amino acids in feedstuffs for poultry' and has been described in the CVB Documentation report nr. 61. As a feed evaluation system has two pillars - the supply of nutrients by the diet on the one hand and the requirement for these nutrients by the animals on the other hand (both expressed in the same units) - it was also necessary to also update and express the amino acid requirements on a standardized ileal digestibility (SID) basis.

Therefore a large meta-analysis dataset was constructed from studies in which amino acid requirements (among others isoleucine and valine) in laying hens were estimated. The estimated amino acid requirements for SID amino acids for laying hens are presented in CVB documentation reports $69-74$. It is known from literature that the dietary concentration of the branched chain amino acid leucine affects the requirement for the amino acids isoleucine and valine. In this CVB documentation report the minimum dietary SID-isoleucine : SIDleucine ratio and the minimum dietary SID-valine : SID leucine ratios are defined.

The outcome of the in this report estimated dietary minimum SID-isoleucine : SID-leucine ratio and minimum dietary SID-valine : SID leucine ratio will be incorporated in the Dutch CVB Tabellenboek Veevoeding Pluimvee 2018 and in the English version CVB Table Poultry Nutrition 2018.

This study was guided and assessed by the Technical Committee of CVB and the Ad hoc group 'SID amino acid requirements for laying hens'

Wageningen, June 2018

J.W. Spek 


\section{Members of the Technical Committee of the CVB}
M. Rijnen (chair)
J. Fledderus
B. Boswerger
A. Dijkslag
H. van Laar
K. Geerse
D. van Manen
J. van der Staak
H. Korterink
A. van de Ven
C. van Vuure
G. van Duinkerken

J.W. Spek
Nederlandse Vereniging Diervoederindustrie (Nevedi)

Nederlandse Vereniging Diervoederindustrie (Nevedi)

Nederlandse Vereniging Diervoederindustrie (Nevedi)

Nederlandse Vereniging Diervoederindustrie (Nevedi)

Nederlandse Vereniging Diervoederindustrie (Nevedi)

Nederlandse Vereniging Diervoederindustrie (Nevedi)

Overleggroep Producenten Natte Veevoeders (OPNV)

Land- en Tuinbouworganisatie Nederland (LTO)

Nederlandse Vereniging van Handelaren in Stro, Fourages en

Aanverwante Producten (HISFA)

Nederlandse Vereniging Diervoederindustrie (Nevedi)

MVO, ketenorganisatie voor oliën en vetten

Wageningen Livestock Research, Dept. Animal Nutrition, Wageningen

Wageningen Livestock Research, Dept. Animal Nutrition, Wageningen

\section{Members of the Ad hoc group 'SID amino acid requirements for laying hens'}
A. Dijkslag
M. van Erp
K. Geerse
A. de Ruijter
J.W. Spek
B. Swart

ForFarmers, Lochem

De Heus, Ede

Trouw Nutrition, Amersfoort

De Hoop, Zelhem

Wageningen Livestock Research, Wageningen

Agrifirm, Apeldoorn 


\section{Contents}

Table of Contents

Page

\section{Preface}

3

Members of the Technical Committee of the CVB …….................................................. 4

Members of the Ad hoc group 'SID amino acid requirements for laying hens' .................... 4

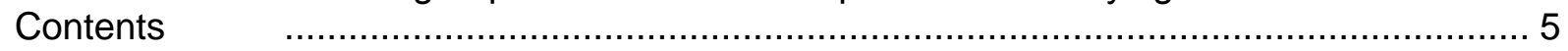

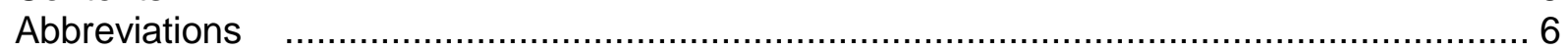

1

2

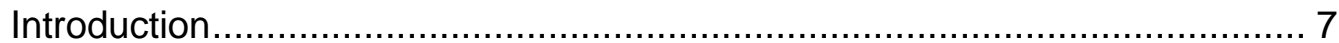

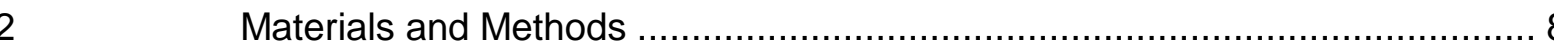

$3 \quad$ Results and Discussion ................................................................. 9

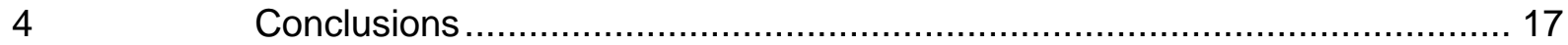

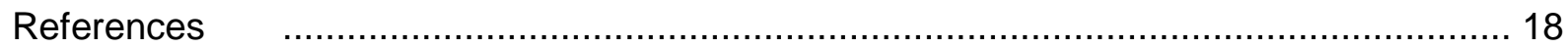




\section{Abbreviations}

$\begin{array}{ll}\text { AA } & \text { Amino acids } \\ \text { CP } & \text { Crude protein } \\ \text { ILE } & \text { Isoleucine } \\ \text { LEU } & \text { Leucine } \\ \text { LYS } & \text { Lysine } \\ \text { SID } & \text { Standardized ileal tract digestible } \\ \text { VAL } & \text { Valine }\end{array}$




\section{Introduction}

It has been observed in rats, pigs and poultry that negative effects of excess concentrations of dietary leucine (LEU) on performance can be offset by increasing the dietary concentration of isoleucine (ILE) and to a lesser extent also by increasing the dietary concentration of dietary valine (VAL). The aim of this study was to establish the minimum required dietary standardized ileal digestible (SID) ILE : LEU ratio and the minimum required dietary SIDVAL:SID-LEU ratio for optimal performance of the laying hen. 


\section{Materials and Methods}

Studies with laying hens were searched in which the effect of dietary SID-ILE:SID-LEU ratios or dietary SID-VAL:SID-LEU ratios on performance were tested. Four studies (Bray, 1970; Muller and Balloun, 1976; Peganova and Eder 2002; Peganova and Eder, 2003) were found that could be used. Because of the large difference in performance (both with respect to egg production rate and egg weight) between the older studies (1970 and 1796) and the new studies (2002 and 2003) and because in one experiment in one study (study of Muller and Balloun, 1976) egg mass and egg weight was not recorded it was decided to express performance also as the egg production rate expressed in \% relative to the maximum observed maximum egg production rate. Expressing performance in this way made it possible to combine the performance data from the various studies. Diets were recalculated using the SID-AA digestibility coefficients of feedstuffs as published in the CVB documentation report nr. 61 (2017).

The study of Bray contained 5 trials in which dietary levels of LEU, ILE and VAL were varied. Furthermore, in the study of Bray, birds were housed individually (individual bird was the experimental unit) and around 10 birds were used for each treatment. The study of Muller and Balloun (1976) contained 3 trials in which dietary levels of LEU, ILE, and VAL were varied. Furthermore, in the study of Muller and Balloun (1976), birds were housed individually (individual bird was the experimental unit) and 6 birds were used for each treatment. The study of Peganova and Eder (2002) contained 4 trials of which 3 trials could be used (the trial that could not be used consisted of a nitrogen balance trial). In the study of Peganova and Eder (2002) the effects of excess ILE on performance was studied. In the study of Peganova and Eder (2002) birds were housed individually (individual bird was the experimental unit) and 12 birds were used per treatment. The study of Peganova and Eder (2003) contained 1 trial in which dietary levels of ILE, VAL, LEU and TRP were varied. In the study of Peganova and Eder (2003) birds were housed individually (individual bird was the experimental unit) and 12 birds were used per treatment. 


\section{Results and Discussion}

Some observations from the study of Muller and Balloun (Results from trial 1 and 2) with CP diets $13 \%, 16 \%$ and $19 \%$ percent were excluded for further analysis due to the very low suboptimal dietary SID-M+C:SID-LYS ratios varying from 59 to $67 \%$.

The relationship between egg production rate relative to the maximum observed egg production rate and the dietary SID-ILE:SID-LEU ratio for the various individual trials is presented in Figure 1. The relationship between egg production rate relative to the maximum observed egg production percentage and the dietary SID-ILE:SID-LEU ratio for the various individual trials is presented in Figure 1. In Figure 2 the same relationship as presented in Figure 1 is shown except that those trials were removed in which the maximum SID-ILE:SIDLEU ratios were lower than $40 \%$. In Figure 3 the relationship between egg mass and dietary SID-ILE:SID-LEU ratio for the various individual trials is presented. In Figure 4 the same relationship as presented in Figure 3 is shown except that those trials were removed in which the maximum SID-ILE:SID-LEU ratios were lower than $40 \%$. 


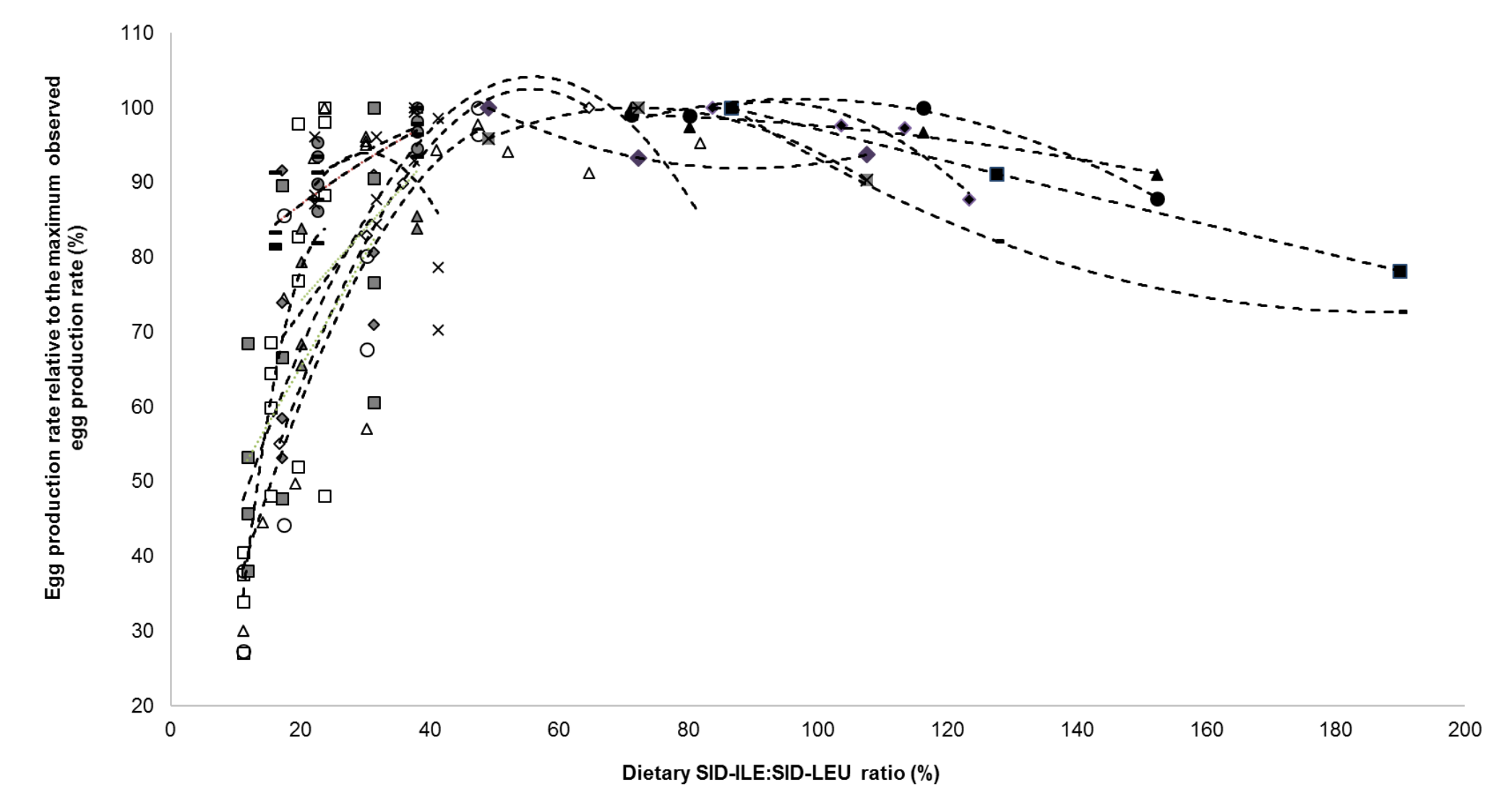

$\diamond$ Bray (1970) Trial 1

口Bray (1970) Trial 4

O Muller and Balloun (1976) Trial 1 R-13\% CP

x Muller and Balloun (1976) Trial 3

- Peganova and Eder (2002) Trial 4

- Peganova and Eder (2003) 3

\section{$\Delta$ Bray (1970) Trial 2}

$\checkmark$ Muller and Balloun (1976) Trial 1 R-10\% CP

口Muller and Balloun (1976) Trial 2 R-10\% CP

- Peganova and Eder (2002) trial 1

- Peganova and Eder (2003) 1

- peganova and Eder (2003) 4
OBray (1970) Trial 3

$\Delta$ Muller and Balloun (1976) Trial 1 D-10\% CP

- Muller and Balloun (1976) Trial 2 R-13\% CP

A Peganova and Eder (2002) Trial 2

x Peganova and Eder (2003) 2

Figure 1. Relationship between egg production rate relative to the maximum observed egg production rate and the dietary SID-ILE:SID-LEU ratio for the various individual trials carried out in the studies of Bray (1970), Muller and Balloun (1976) and Peganova and Eder (2002, 2003). The dashed curved lines are the second order polynomial relationships fitted to the individual trials. 


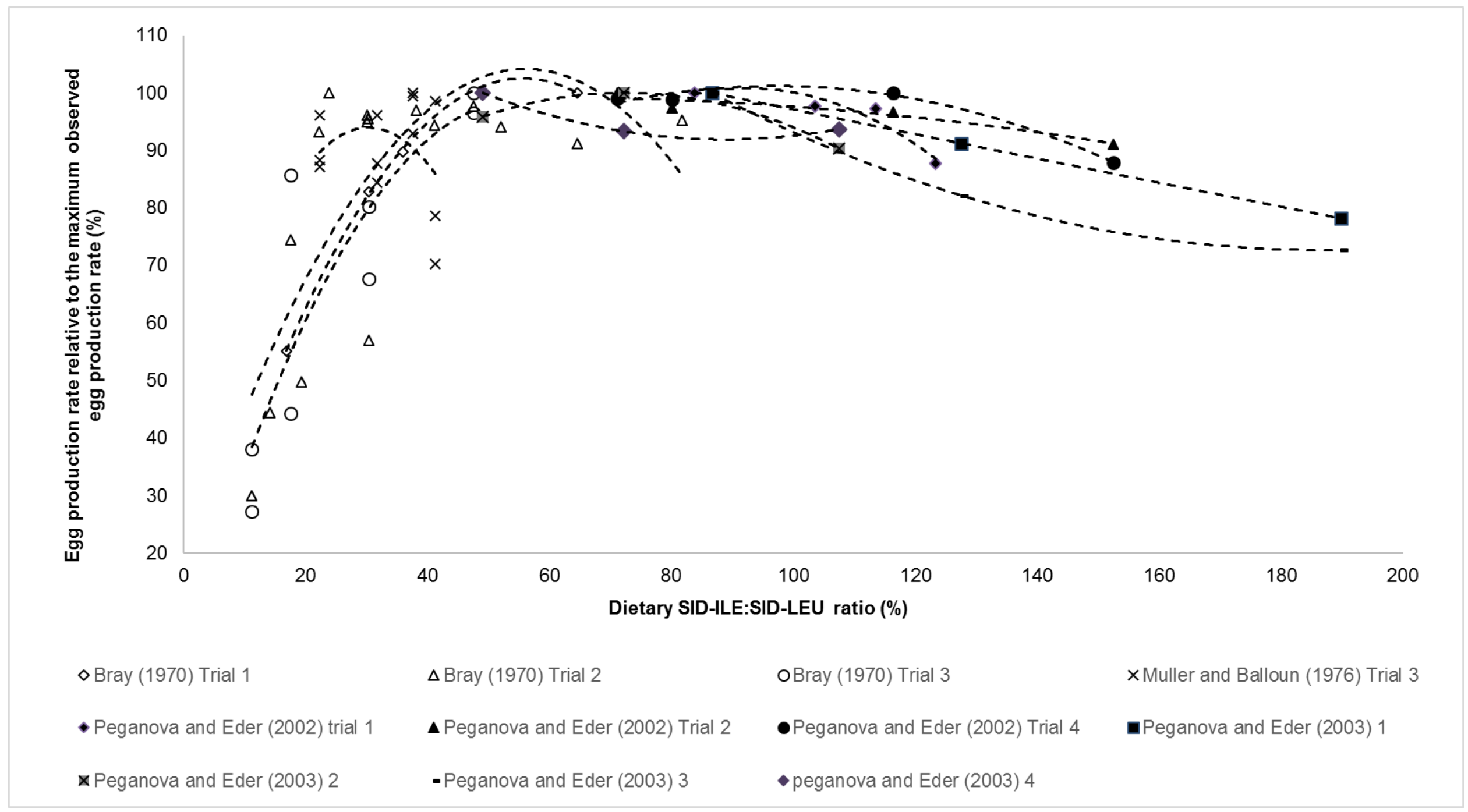

Figure 2. Relationship between egg production rate relative to the maximum observed egg production rate and the dietary SID-ILE:SID-LEU ratio for the various individual trials carried out in the studies of Bray (1970), Muller and Balloun (1976) and Peganova and Eder (2002, 2003). The dashed curved lines are the second order polynomial relationships fitted to the individual trials. Only those trials are shown in which the maximum SID-ILE:SID-LEU ratios exceeded $40 \%$. 


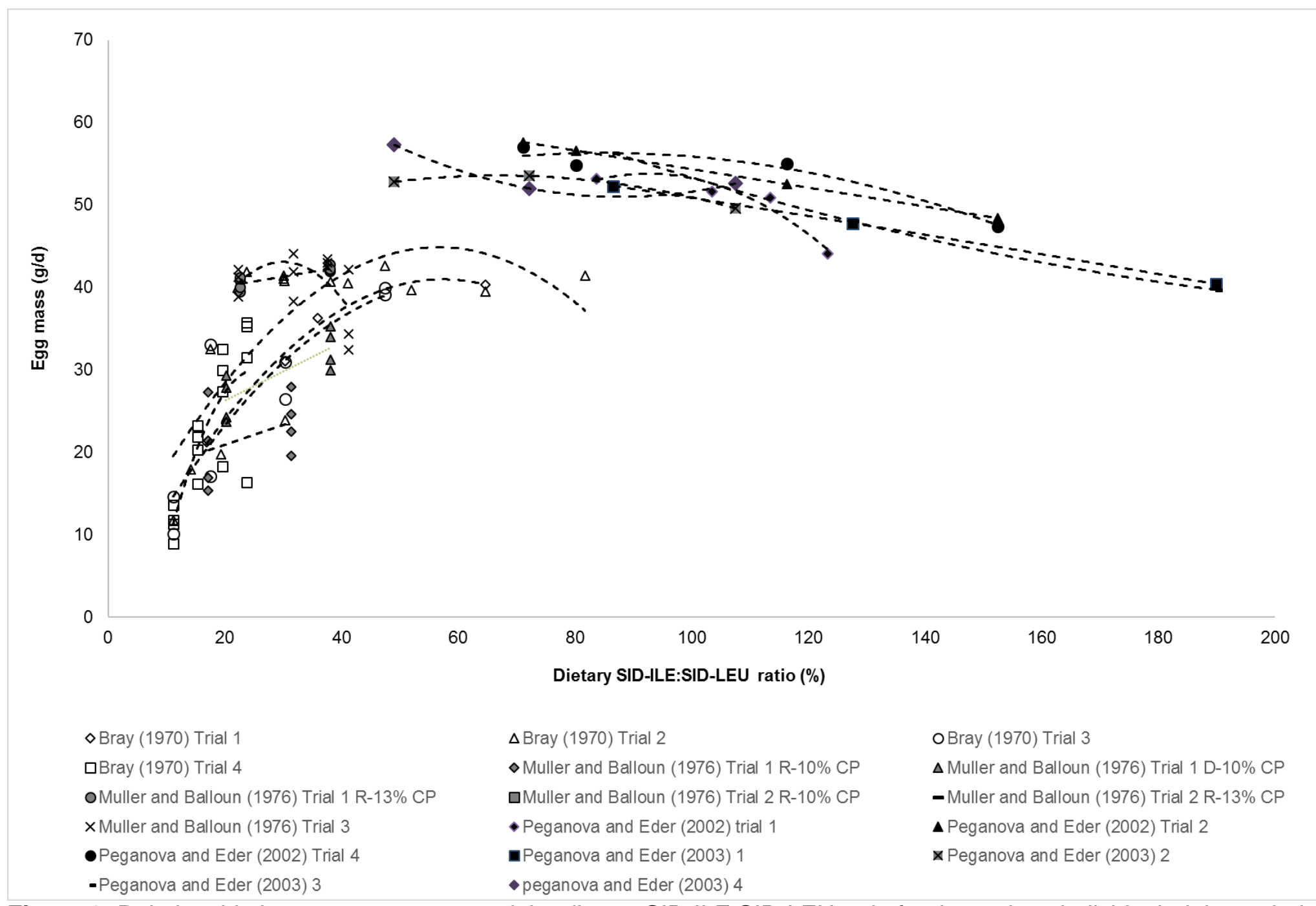

Figure 3. Relationship between egg mass and the dietary SID-ILE:SID-LEU ratio for the various individual trials carried out in the studies of Bray (1970), Muller and Balloun (1976) and Peganova and Eder (2002, 2003). The dashed curved lines are the second order polynomial relationships fitted to the individual trials. 


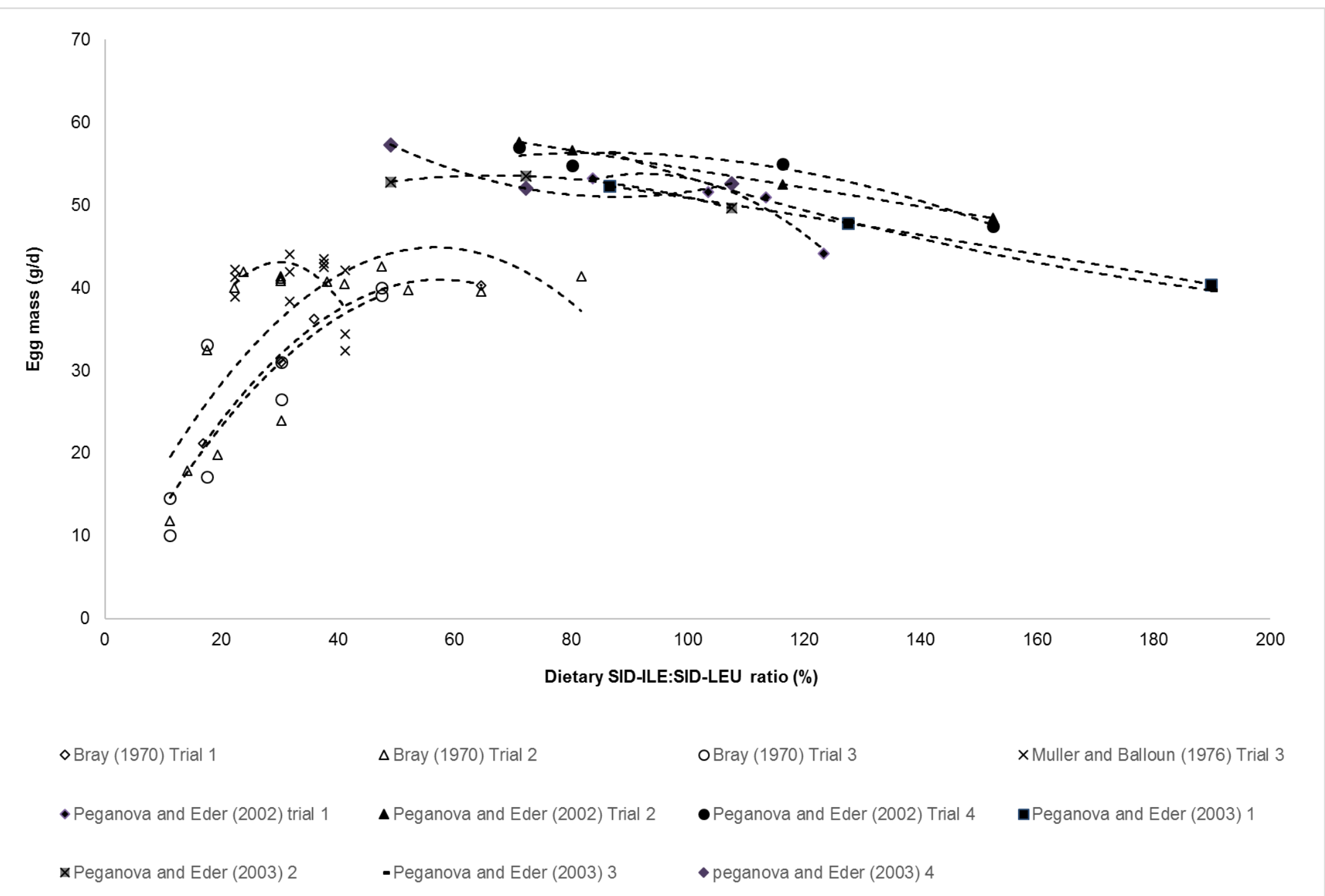

Figure 4. Relationship between egg mass and the dietary SID-ILE:SID-LEU ratio for the various individual trials carried out in the studies of Bray (1970), Muller and Balloun (1976) and Peganova and Eder (2002, 2003). The dashed curved lines are the second order polynomial relationships fitted to the individual trials. Only those trials are shown in which the maximum SID-ILE:SID-LEU ratios exceeded $40 \%$. 
It was also checked whether the (SID-ILE + SID-VAL):SID-LEU ratio would increase the accuracy in which egg mass or the relative egg production rate could be estimated compared to the SID-ILE:SID-LEU ratio. However, this was not the case. For example, when fitting a $4^{\text {th }}$ order polynomial relation through the pooled dataset of observations the amount of explained variation was higher when using the SID-ILE:SID-LEU ratio for estimating the relative egg production rate ( $R^{2}$ of 0.615 versus 0.516 ) and also for estimating egg mass ( $R^{2}$ of 0.753 versus 0.697 ). This does not mean that VAL is not important as some studies show that at increased dietary LEU both ILE and VAL should be added in order to annul the negative effects of excess LEU. It is simply the result of the experimental contrasts in the trials in the present dataset in which for most cases dietary SID-ILE was varied and not dietary SID-VAL.

However, in a few trials dietary VAL was varied. In Figure 5 the relationships between egg mass and dietary SID-VAL:SID-LEU are shown using the results of these trials in which dietary VAL was varied. As a point of precaution, it should be noted that the corresponding SID-ILE:SID-LEU ratios of trials presented in Fig. 5 varied between $17-24 \%$ and likely were suboptimal (too low). The relationships between egg mass and dietary SID-VAL:SID-LEU shown in Fig. 5 may have been different in case the dietary SID-ILE:SID-LEU would have been higher. A visual analysis of results in Figure 5 indicate an optimal dietary SID-VAL:SIDLEU ratio of around $25 \%$.

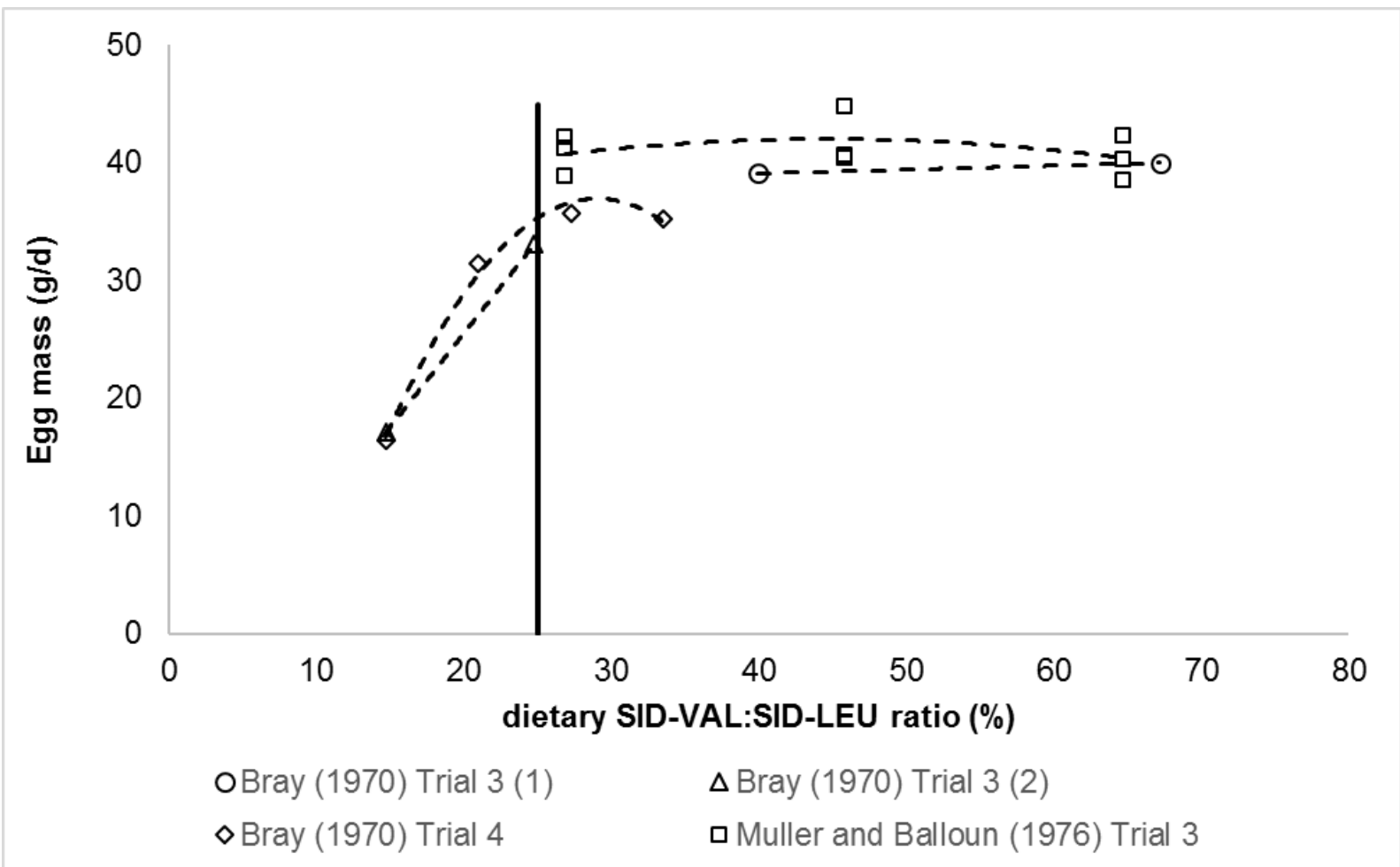

Figure 5. Relationship between egg mass and the dietary SID-VAL:SID-LEU ratio for the various individual trials carried out in the studies of Bray (1970) and Muller and Balloun (1976). The dashed curved lines are the second order polynomial relationships fitted to the individual trials. The proposed minimum SID-VAL:SID-LEU ratio of $25 \%$ is made visible by the black vertical line. 
From a visual analysis of the relationships presented in Fig. $1-4$ it seems that a minimum dietary SID-ILE:SID-LEU ratio of 45\% is enough for optimal performance. In Figures 6 and 7 a SID-ILE:SID-LEU ratio of $45 \%$ is made visible by the black vertical line.

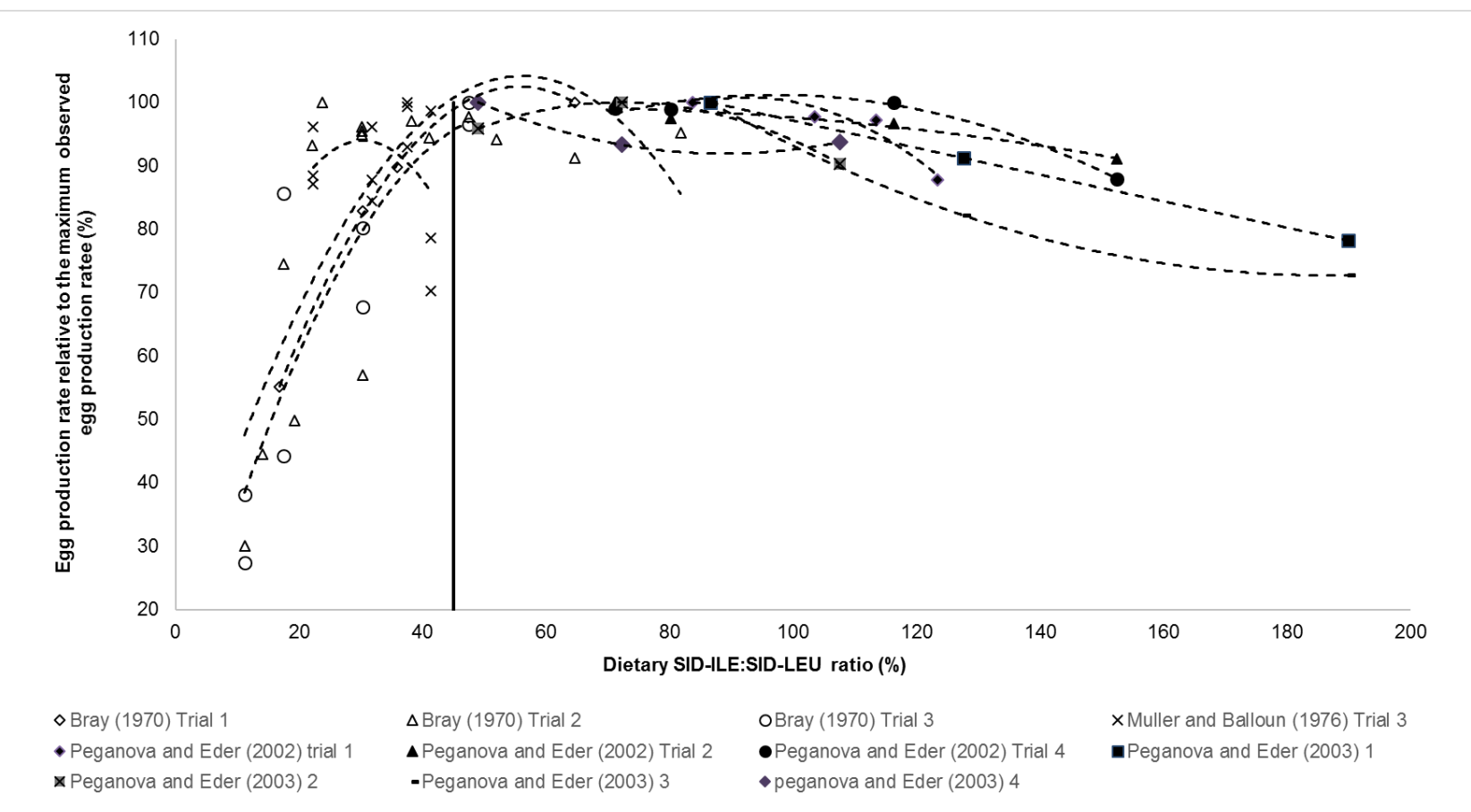

Figure 6. Relationship between egg production rate relative to the maximum observed egg production rate and the dietary SID-ILE:SID-LEU ratio for the various individual trials carried out in the studies of Bray (1970), Muller and Balloun (1976) and Peganova and Eder (2002, 2003). The dashed curved lines are the second order polynomial relationships fitted to the individual trials. Only those trials are shown in which the maximum SID-ILE:SID-LEU ratios exceeded $40 \%$. The proposed minimum SID-ILE:SID-LEU ratio of $45 \%$ is made visible by the black vertical line. 


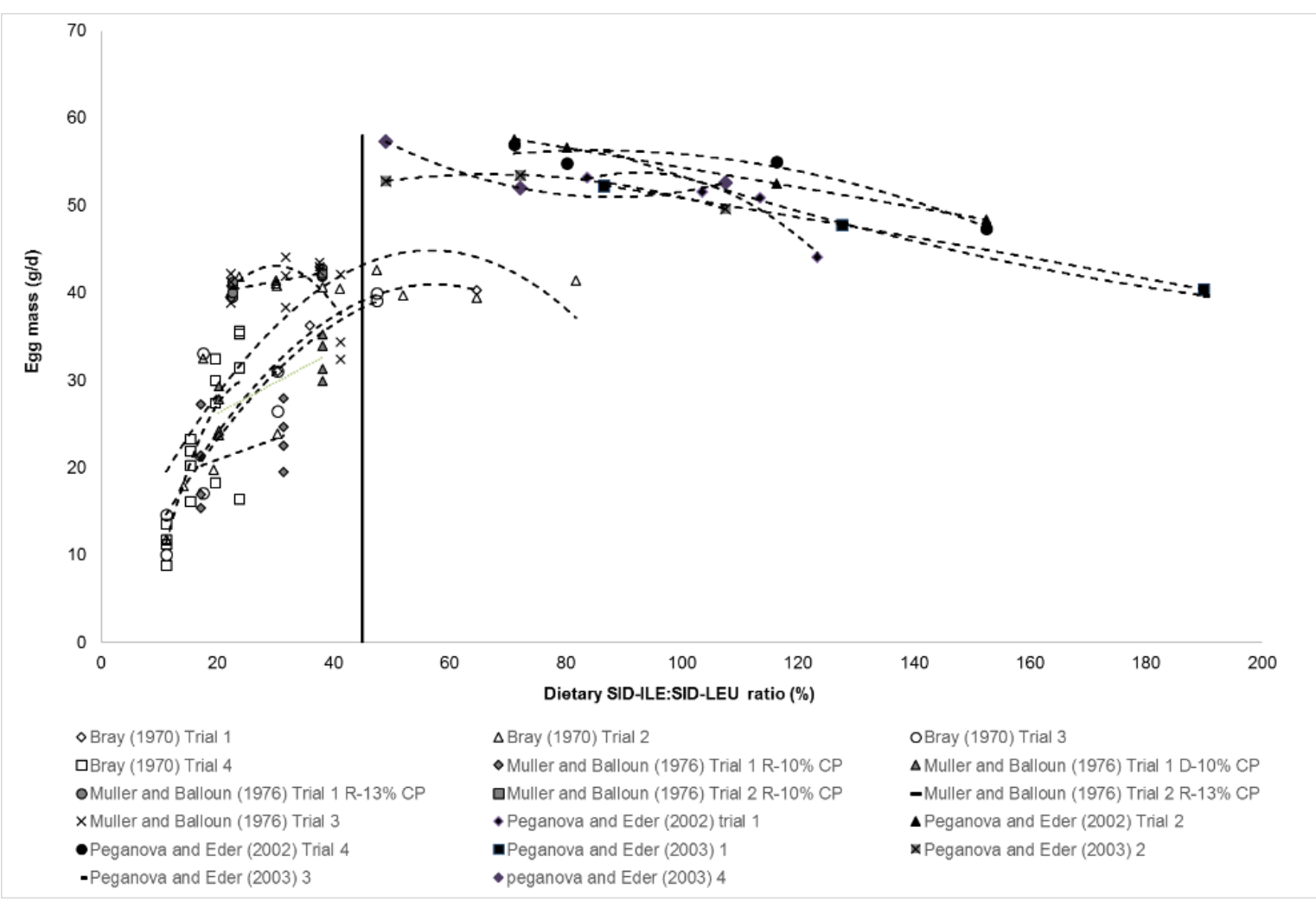

Figure 7. Relationship between egg mass and the dietary SID-ILE:SID-LEU ratio for the various individual trials carried out in the studies of Bray (1970), Muller and Balloun (1976) and Peganova and Eder $(2002,2003)$. The dashed curved lines are the second order polynomial relationships fitted to the individual trials. The proposed minimum SID-ILE:SIDLEU ratio of $45 \%$ is made visible by the black vertical line. 


\section{Conclusions}

Based on the limited information available it is concluded that the minimum SID-ILE:SID-LEU ratio is $45 \%$ and that the minimum SID-VAL:SID-LEU ratio is $25 \%$. With respect to a minimum SID-VAL:SID-LEU ratio of $25 \%$, such a value in practice will not occur as the feedstuff with the lowest SID-VAL:SID-LEU ratio in the CVB Table (maize gluten meal) already has a ratio of $27 \%$ (maize, wheat, rape meal and soybean meal have ratios of 38,64 , 70 and $62 \%$, respectively).

With respect to a minimum SID-ILE:SID-LEU ratio of $45 \%$ such a ratio might occur in practise when low protein diets are used and especially when using maize/sorghum based feed stuffs and blood-meal/meat-meal as these feedstuffs have ratios lower than $46 \%$ (see Table 1 underneath).

Table 1. CVB Table 2018 values for feedstuffs with SID-ILE:SID-LEU ratios lower than $46 \%$.

\begin{tabular}{ll}
\hline Feedstuff & $\begin{array}{c}\text { SID-ILE:SID-LEU } \\
\text { ratio }\end{array}$ \\
\hline Bloodmeal, spray dried & 6 \\
Maize gluten meal & 24 \\
Maize & 28 \\
Maize, chemical/heat treated & 28 \\
Maize germ meal feed, solvent extracted & 29 \\
Maize feed meal & 29 \\
Sorghum gluten meal & 30 \\
DDGS, Maize & 30 \\
Maize feed flour & 30 \\
Maize bran & 31 \\
Maize germ meal feed expeller & 31 \\
Sorghum & 31 \\
Maize germ meal, solvent extracted & 32 \\
Maize gluten feed & 32 \\
Maize gluten feed & 32 \\
Maize gluten feed & 32 \\
Millet & 33 \\
Millet, (pearl millet) & 33 \\
Meat meal, Dutch origin & 44 \\
Meat meal & 45 \\
Meat meal & 45 \\
DDGS, wheat based & 45 \\
\hline
\end{tabular}




\section{References}

Blok, M. C. and R. A. Dekker. 2017. Table 'Standardized ileal digestibility of amino acids in feedstuffs for poultry'. CVB Documentation report nr. 61.

Bray, D. J. 1970. The isoleucine and valine nutrition of young laying pullets as influenced by excessive dietary leucine. Poultry science, 49, 1334-1341.

Muller, R. D. \& Balloun, S. L. 1976. Leucine imbalance in corn-soybean meal diets for laying hens. Poultry science, 55, 487-496.

Peganova, S. \& Eder, K. 2002. Studies on requirement and excess of isoleucine in laying hens. 81, 1714-1721.

Peganova, S. \& Eder, K. 2003. Interactions of various supplies of isoleucine, valine, leucine and tryptophan on the performance of laying hens. Poultry Science, 82, 100-105. 